\title{
CONCEPÇÕES DOCENTES SOBRE O USO DAS TECNOLOGIAS NA EDUCAÇÃ̃O
}

\section{TEACHER CONCEPTIONS ON THE USE OF TECHNOLOGIES IN EDUCATION}

\author{
Ana Claudia Loureiro, UNASP, aloureiro@usp.br \\ Carolina Costa Cavalcanti, UNASP, carolinacavalcanti.ead@gmail.com \\ Cristina Zukowsky - Tavares, UNASP, cristina.tavares@unasp.edu.br
}

\begin{abstract}
Resumo: Este estudo objetivou relatar as concepções do professor sobre o uso das TIC na educação e a mudança dessas concepções após uma formação docente pautada na vivência de modelos pedagógicos, habilidades e organização que pudessem ser incorporados às práticas docentes. Para atendimento do objetivo do estudo foram comparadas as respostas de dois questionários aplicados a 36 docentes para verificar a utilização das TIC em seu cotidiano escolar. Os resultados indicaram que a maioria adota as tecnologias, mas ainda não sabe integrá-las à prática pedagógica. Após a formação recebida, as professoras apresentaram mudança de concepção e intenção de modificar a prática adotada, incorporando as TIC e as estratégias ativas em suas aulas.
\end{abstract}

Palavras-chave: Formação de professores. Tecnologias e Educação. Práticas pedagógicas.

\begin{abstract}
This study aimed to report teacher's conceptions about the use of ICTs in education and the chance these views after a teacher training based on the experience of pedagogical models, skills and organizational that could be incorporated into teaching practices. To meet the study objective, the responses of two questionnaires applied to 36 teachers were compared to verify the use of ICT in their daily school life. The results indicated that most adopt the technologies, but do not know how to integrate them into the pedagogical practice. After the training received, the teachers presented a change of conception and the intention to modify the adopted practice, incorporating the ICT and the active strategies in their classes.
\end{abstract}

Keywords: Teachers Training. Education and technologies. Pedagogical practices.

\section{Introdução}

O presente estudo se enquadra nos múltiplos que estão a se realizar, por parte de instituições educacionais públicas e de grupos de pesquisa para a formação docente na era digital, reconhecendo a importância que essa formação representa para as políticas públicas educacionais e para a mudança de práticas pedagógicas que integrem as tecnologias digitais emergentes nos processos de aprendizagem em contexto escolar.

A utilização das TIC na educação deve estar inserida em um contexto pedagógico, como um recurso didático, que transcenda a ideia do simples domínio da técnica abrangendo, também, o domínio da leitura dos mecanismos de comunicação e informação, possibilitando o desenvolvimento de competência a fim de que “[...] o educando saia do status de simples espectador ou receptor, para converter-se em recriador ou autor da história" (Gutierrez, 1978, p.66). Nessa linha de pensamento, torna-se apropriada a argumentação de Behrens.

Trata-se de aliar a formação ético-humanística aos desafios tecnológicos-científicos, sob pena de construir uma sociedade produtiva e, ao mesmo tempo, agressiva, racional e desumana, acentuando os problemas e as injustiças sociais. O homem precisa se apropriar da técnica e coloca-la a seu serviço, buscando uma melhor qualidade de vida para si e seus semelhantes. (2000, p. 72).

Consequentemente, esses desafios repercutem na profissão docente. Destaca-se a necessidade das tecnologias estarem inseridas nos processos educativos como um recurso que potencialize a ação humana transformadora para um pensar crítico, reflexivo, criativo e inovador de educadores e educandos. Com a consciência de que a prática docente constitui-se de uma prática carregada de saber incorporado pelo professor e, para que essa 
prática não seja limitada a somente uma função executiva e prático-utilitária da educação, torna-se necessário formar docentes para uma realidade educacional marcada pelas novas tecnologias.

O Ministério da Educação, no ano 2000, já apontava para a necessidade de redimensionar a formação dos professores preparando-os para as mudanças propostas para a educação básica. Segundo o documento,

No mundo contemporâneo, o papel do professor está sendo questionado e redefinido de diversas maneiras. Para isso concorrem as novas concepções sobre a educação, as revisões e atualizações nas teorias de desenvolvimento e aprendizagem, o impacto da tecnologia da informação e das comunicações sobre os processos de ensino e aprendizagem, suas metodologias e materiais de apoio. Tudo isso delineia um cenário educacional com exigências para cujo atendimento os professores não foram, nem estão sendo preparados. (Brasil, 2000, p.5).

Diante desse contexto, o objetivo deste trabalho foi o de conhecer e analisar as concepções do professor sobre o uso das TIC na educação visando a promover uma formação docente pautada na vivência de novos modelos pedagógicos, habilidades e modos de organização que pudessem ser incorporados às práticas docentes.

O estudo foi realizado com duas turması da disciplina "Tecnologia na Infância" do curso "Alfabetização e Letramento", da pós-graduação em Educação do Centro Universitário Adventista de São Paulo (UNASP) nos anos de 2017 e 2018. Para a coleta de dados foram aplicados questionários às docentes. Buscamos responder, assim, às seguintes questões que nortearam o estudo: Qual a concepção dos professores sobre a utilização das tecnologias em ações educativas? De que maneira uma formação docente, pautada em procedimentos didáticos inovadores, pode conduzir a uma mudança de paradigma e auxiliar na mudança das práticas pedagógicas?

Dentro desse cenário, o design da disciplina "Tecnologia na Infância" foi criado com atividades desafiadoras e modelo pedagógico fundamentado em metodologias ativas de aprendizagem, segundo as contribuições de Bergmann \& Sams (2017), Bacich \& Moran (2018), Filatro \& Cavalcanti (2018), oportunizando experiências metodológicas que visavam a capacitar as docentes a integrarem as TIC em diversas atividades pedagógicas desenvolvidas no âmbito escolar.

Como ponto inicial, entendemos que seria preciso fazer uma análise e reflexão das concepções dessas professoras quanto ao uso das tecnologias na sala de aula com o objetivo de obter informações que permitissem identificar como essa concepção se reflete no trabalho pedagógico (Tardif, 2002; Gauthier, 2006).

\section{Saberes Docentes: Concepções inseridas na prática pedagógica}

Dentre os questionamentos mais frequentes com que nos deparamos, ao longo das investigações na área da formação docente, alguns adquirem maior relevância: Que saberes são necessários ao desenvolvimento do professor para que ele possa ensinar e para que seu ensino possa conduzir ao aprendizado do aluno? Como um curso de formação, direcionado a professores, pode conduzir a mudanças de paradigmas que refletem em novas práticas pedagógicas? Como os professores aprendem a ensinar?

Segundo Tardif (2002), o saber docente é um "[...] saber plural formado pelo amálgama mais ou menos coerente de saberes oriundos da formação profissional e de saberes disciplinares, curriculares e experienciais" (p.54). O autor destaca a existência de 
quatro tipos diferentes de saberes implicados na atividade docente, apresentados no Quadro 1.

Quadro 1 - Saberes presentes na atividade docente

\begin{tabular}{l|l}
\hline Saber & Origem \\
\hline Profissional & $\begin{array}{l}\text { Da formação inicial: das Ciências da Educação e da ideologia } \\
\text { pedagógica. }\end{array}$ \\
\hline Disciplinar & $\begin{array}{l}\text { Dos diferentes campos do conhecimento: linguagem, ciências } \\
\text { exatas, ciências humanas, ciências biológicas etc. }\end{array}$ \\
\hline Curricular & $\begin{array}{l}\text { Dos programas escolares: objetivos, conteúdos, métodos que } \\
\text { os professores devem aprender e aplicar. }\end{array}$ \\
\hline Experimental & $\begin{array}{l}\text { Saberes que resultam do próprio exercício da atividade } \\
\text { profissional dos professores por meio da vivência de situações } \\
\text { específicas relacionadas ao espaço da escola e às relações } \\
\text { estabelecidas com os alunos e colegas de profissão. }\end{array}$ \\
\hline
\end{tabular}

Fonte: Adaptado de Tardif (2002)

Dentro dessa tipologia de saberes, Tardif evidencia os saberes experienciais, justificando essa "posição de destaque" pela relação de exterioridade que os professores mantêm com os saberes curriculares, disciplinares e da formação pedagógica, uma vez que não controlam sua produção e sua circulação. Essa relação de exterioridade, mantida pelos professores com esses saberes, faz com que valorizem ainda mais os seus saberes experienciais, visto que é sobre eles que os professores mantêm controle, tanto na produção quanto na sua legitimação. Em sua prática pedagógica cotidiana, os professores vivenciam situações concretas que exigem habilidades, capacidade de interpretação e improvisação, saber lidar com situações inusitadas e de conflito, ter segurança para decidir qual a melhor estratégia a seguir, diante do evento apresentado. Cada situação do cotidiano pedagógico não é exatamente igual à outra, mas trazem entre si certas proximidades que permitem ao professor transformar algumas de suas estratégias de sucesso em práticas prévias para a solução de situações semelhantes, agregando um habitus específico à sua profissão.

Gauthier et al. (2006), reitera a forma plural de entender os saberes docentes apresentada por Tardif. Para o autor, é necessário entender que a prática docente é carregada de um conjunto de saberes, sendo um deles, específico à classe profissional dos professores, que é o saber da ação pedagógica, resultado da relação estabelecida entre os demais saberes do professor. Esse saber traz em si o repertório de conhecimentos de ensino que direcionam as ações do docente mediante as diversas situações de sala de aula. Constitui-se pelas representações que cada professor possui da escola, do professor, dos alunos, dos processos de ensinar e aprender etc. Para os autores, essas representações foram construídas anteriormente ao ingresso da carreira docente, antes mesmo do professor decidir sobre sua profissão e ingressar num curso de formação inicial

Sendo assim, neste estudo demos ênfase à compreensão dos saberes da ação pedagógica e dos saberes experienciais (Tardif, 2002; Gauthier et al., 2006) buscando identificar como esses saberes influenciam, ou não, a prática docente no uso pedagógico das tecnologias como ferramentas fecundas para o processo de ensino e aprendizagem. Entendemos que a necessidade de investigar essas percepções possibilita obtermos pistas para melhorar os cursos de formação continuada, visando a proporcionar ao professor uma reflexão sobre sua ação pedagógica, avaliando novos modos de ensinar e aprender na contemporaneidade. 


\section{Metodologias ativas na formação de professores}

A aprendizagem mediada pelas TIC envolve mais do que a simples incorporação de tecnologias de ponta em contextos escolares (Bates, 2016). Práticas significativas adotadas no campo educacional geralmente partem da definição de objetivos de aprendizagem e contam com o uso integrado de metodologias de aprendizagem e tecnologias de suporte (Behar, 2009).

Por isso, as TIC devem ser adotadas na escola não como um fim, mas como como um meio para dar suporte às ações pautadas em modelos didático-pedagógicos que colocam o aluno como protagonista de sua própria aprendizagem (Bergmann \& Sams, 2017, Bacich \& Moran, 2018).

As metodologias ativas são abordagens, estratégias e técnicas de aprendizagem individual e colaborativa que, segundo Filatro e Cavalcanti (2018) engajam os alunos enquanto realizam atividades práticas e desenvolvem projetos que articulam teoria e prática. As autoras explicam que "nos contextos em que são adotadas, o aprendiz é visto como um sujeito ativo, que deve participar de forma intensa de seu processo de aprendizagem (mediado ou não por tecnologias), enquanto reflete sobre aquilo que está fazendo" (p. 12). Indicam que existem três princípios que caracterizam as metodologias ativas: a) protagonismo do aluno: centralidade no ser humano e nas atividades vinculadas à prática educativa. b) colaboração: produção colaborativa e/ou cocriação de conhecimentos, com enfoque tanto no processo quanto no produto da aprendizagem. c) ação-reflexão: articulação de teoria e prática pela interação do aprendiz com o mundo.

O uso de metodologias ativas na formação de professores é um caminho eficaz para possibilitar que vivenciem experiências de aprendizagem que depois poderão ser transpostas para os contextos onde atuam como educadores. A prática de permitir que os docentes vivenciem momentos de ação e reflexão advém do conceito de homologia de processos proposto por Schön (2009) em sua obra sobre a formação do profissional reflexivo. Isso significa que os professores devem ser formados pela adoção das estratégias esperadas que os mesmos usem em seu exercício profissional.

As metodologias ativas, Sala de Aula Invertida, Brainstorming, Mapa Mental e Peer Instruction, adotadas nesse estudo em uma disciplina de curso de especialização lato sensu, visavam fomentar a aprendizagem de conteúdos curriculares do programa e a adoção de modelos pedagógicos inovadores, possíveis de serem incorporados nos contextos educacionais onde os docentes atuam.

\section{Procedimentos metodológicos}

O curso de especialização lato sensu em "Alfabetização e Letramento" foi elaborado para professores da Educação Infantil e Ensino Fundamental I com o propósito de conduzir a processos de ensino e aprendizagem que possibilitassem ao docente ampliar seu conhecimento e formação quanto às contribuições teóricas mais recentes para a condução dos processos educativos em sala de aula, de modo inovador e centrado na aprendizagem do aluno. Dentro dessa proposta, foi criada a disciplina "Tecnologia na Infância”, objeto deste estudo, cujo objetivo é refletir sobre o papel da tecnologia nos processos educativos na fase inicial da escolarização, dentro de uma proposta de formação pautada na vivência de novos modelos pedagógicos, habilidades e modos de organização que venham a ser incorporados às práticas docente, conforme proposto por Almeida (2005).

Para assegurar a articulação teórico-prática, o design da disciplina foi estruturado com atividades desafiadoras e modelos didáticos fundamentados em metodologias e 
estratégias ativas de aprendizagem, segundo as contribuições de Bergmann \& Sams (2017), Bacich \& Moran (2018), Filatro \& Cavalcanti (2018), oportunizando aos professores experiências metodológicas que visavam capacitar o docente a usar as TIC em diversas atividades pedagógicas desenvolvidas no âmbito escolar. A disciplina tem uma carga horaria de 30 horas distribuídas em 6 semanas.

Inicialmente, logo na primeira aula, foram apresentados o plano de ensino, objetivos e instrumentos de avaliação da disciplina, bem como foi aplicado o primeiro questionário (Q1), criado no aplicativo Google Formulário, que discorria sobre o uso das TIC na educação. O Q1 apresentava três blocos de perguntas: Bloco I - Identificação, com sete questões sobre a caracterização das participantes; Bloco II - Fluência Digital, com doze questões sobre as habilidades tecnológicas quanto ao uso das TIC em atividades diárias e profissionais e o Bloco III - Usabilidade das TIC na Educação, com seis questões sobre a percepção docente quanto ao uso educativo das TIC.

Os dados deste estudo são oriundos de duas turmas do curso: uma turma do segundo semestre de 2017, com 16 participantes e uma turma do primeiro semestre de 2018, com 20 participantes, totalizando 36 participantes.

Os dados coletados no Bloco I, Q1, demonstram que as participantes do curso eram todas do sexo feminino, professoras da Educação Infantil e do 1o e 2o anos do Ensino Fundamental, que atuavam em seis escolas privadas da rede Adventista da cidade de São Paulo/SP, Brasil. As participantes tinham, em sua maioria, idade entre 30 e 39 anos (75\%), seguida das que tinham entre 40 e 49 anos (11\%); acima de 50 anos somavam 8\% e com idade entre 20 e 29 anos representavam 6\%. No tocante à formação inicial, quase a totalidade $(94,4 \%)$ era licenciada em Pedagogia. Entre as demais $(5,6 \%)$ licenciadas em Letras e nenhuma (0\%) possuía uma Pós-Graduação Lato Sensu ou Stricto Sensu.

\section{Gráfico 1 - Caracterização das participantes}

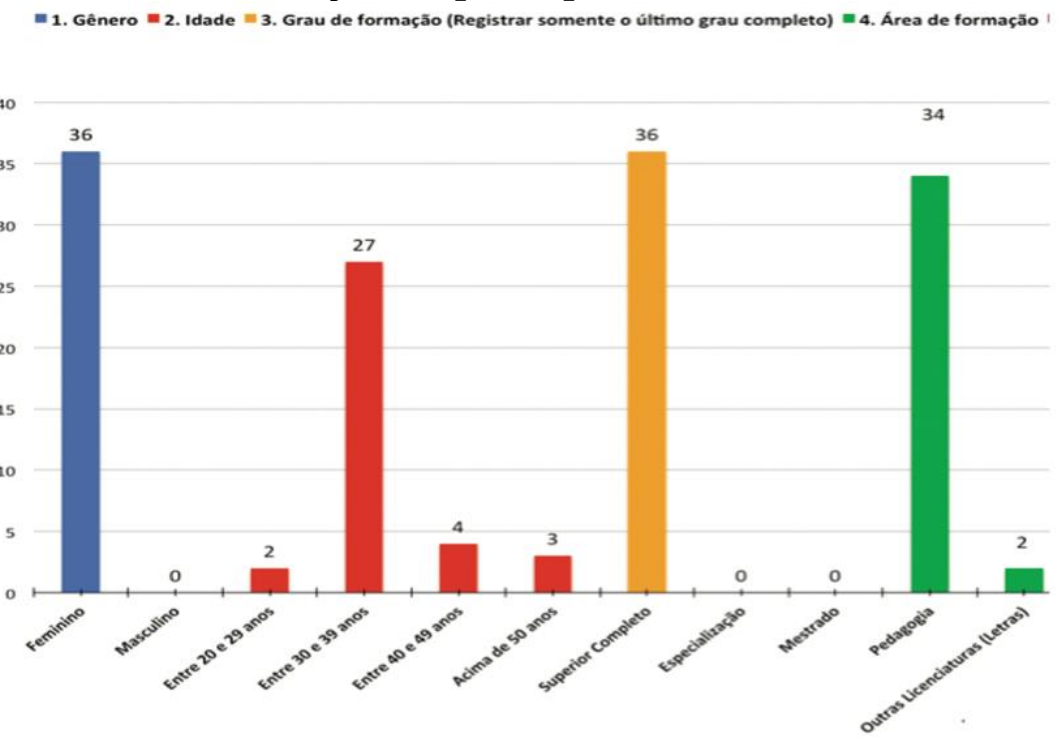

Fonte: Gráfico extraído do Questionário 1, Bloco I, feito no aplicativo Google Formulários.

Continuando a análise, em relação ao Bloco II - Fluência digital do Q1, observase, no gráfico 2 , que $83 \%$ das alunas utilizavam os recursos digitais de casa; $77,7 \%$ diziam ter facilidade no uso da tecnologia e a utilizavam com frequência; $91 \%$ acessavam a internet diariamente e $86,1 \%$, utilizavam a internet para o trabalho. O dispositivo digital mais utilizado, apresentado na pesquisa, foi o notebook (50\%), seguido do smartphone $(36,1 \%)$ e do computador $(13,8 \%)$. 
Gráfico 2- Fluência Digital das participantes

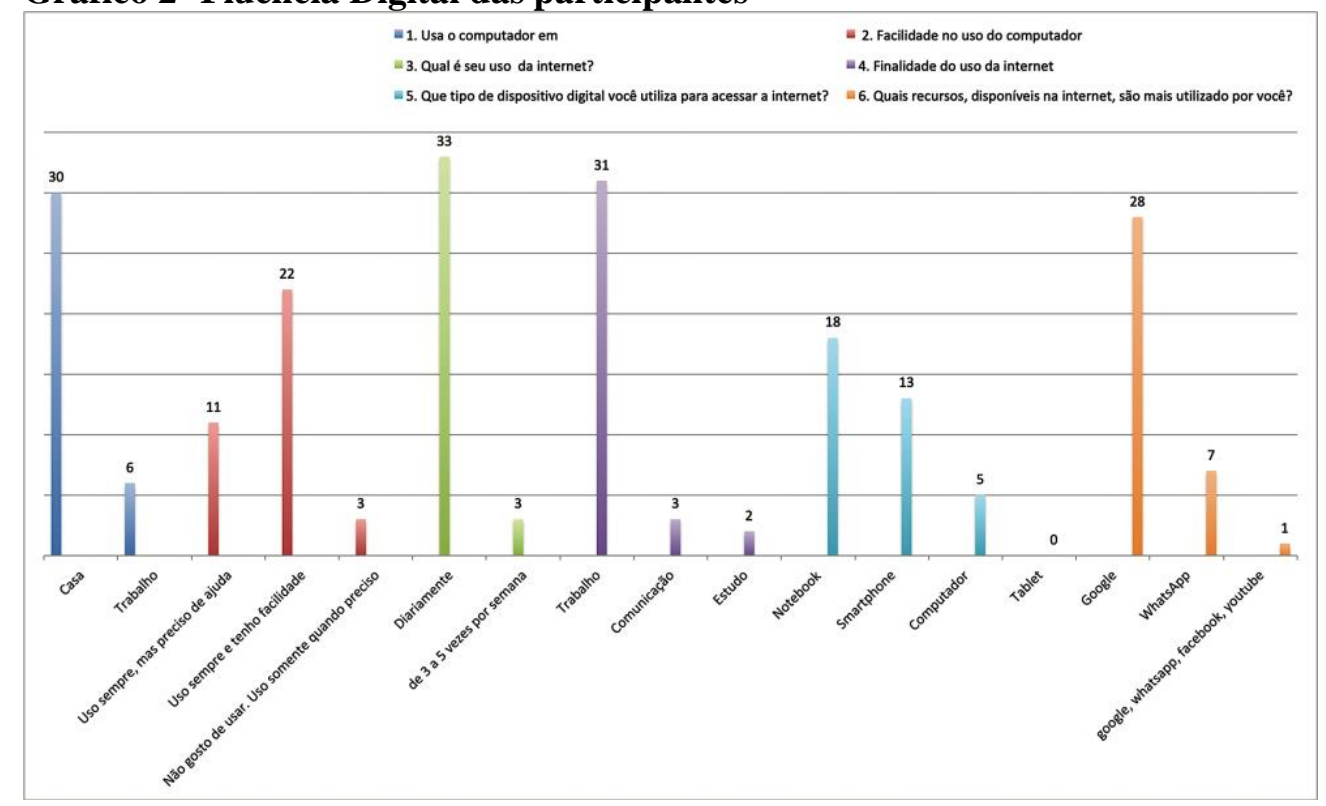

Fonte: Gráfico extraído do Questionário 1, Bloco II, feito no aplicativo Google Formulários.

O gráfico 3, pertence ao terceiro bloco do Q1 e tinha o objetivo de coletar dados sobre as concepções das participantes quanto ao uso das TIC em processos educacionais. As questões eram objetivas e apresentavam uma escala estilo Likert2, com intensidade entre "concordo com a afirmativa (1) à discordo com a afirmativa (3).

\section{Gráfico 3 - Percepção das participantes quanto ao uso das TIC na educação}

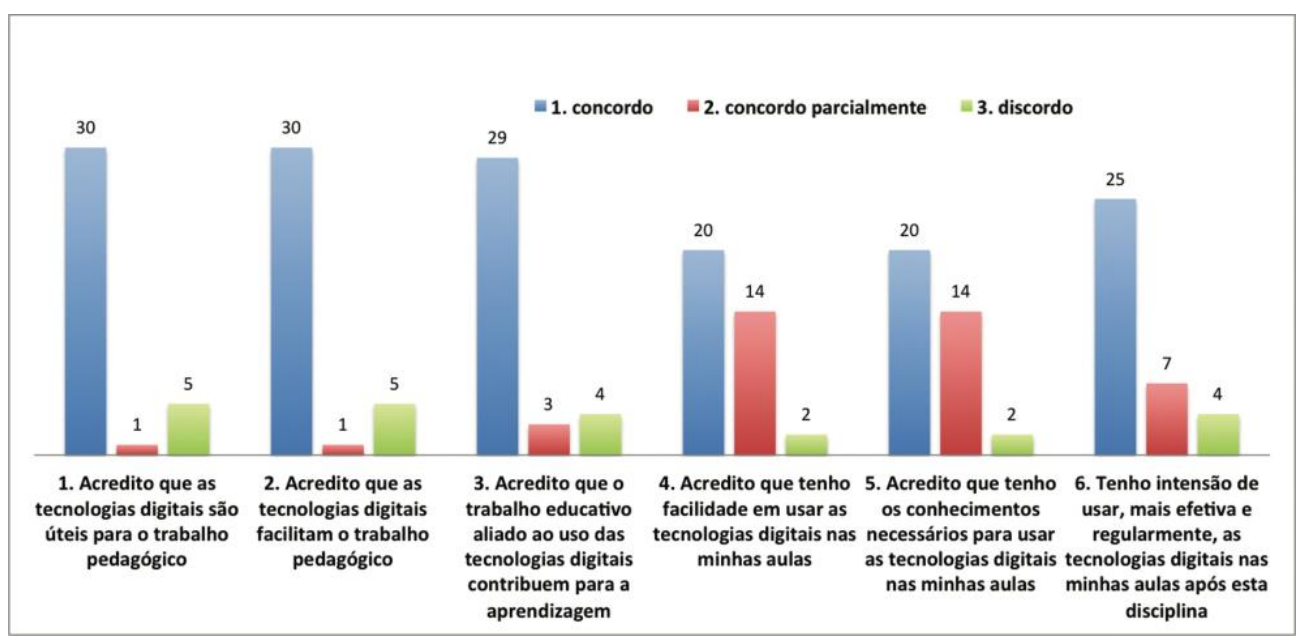

Fonte: Gráfico extraído do Questionário 1, Bloco III, feito no aplicativo Google Formulários.

As seis questões desse bloco tinham o objetivo de coletar a percepção inicial das participantes quanto ao uso das TIC no processo de ensino e aprendizagem.

Quanto à utilidade das tecnologias para o trabalho pedagógico observa-se que, do total de 36 respondentes, $83,3 \%$ (30) concordam que a tecnologia é útil para o trabalho pedagógico, $13,8 \%$ (5) discordam e 2,7\% (1) concorda parcialmente. Destaca-se, como dado significativo, que a maioria das participantes acreditava que as tecnologias digitais são úteis para o trabalho pedagógico. No entanto, há um número expressivo que

2 Escala Likert é uma escala de resposta psicométrica amplamente adotada em pesquisas quantitativas. 
manifestou não comungar dessa mesma concepção. Isso pode denotar falta de conhecimento quanto ao potencial das tecnologias para o processo de ensino e aprendizagem e este foi um dado importante para tomada de decisão no planejamento e condução da disciplina.

$\mathrm{Na}$ questão seguinte, que tratava da tecnologia como um recurso facilitador do trabalho pedagógico, observa-se a mesma porcentagem de respostas: $83,3 \%$ (30) concordam, $13,8 \%$ (5) discordam e 2,7\% (1) concorda parcialmente.

A discussão na terceira pergunta visava a coletar dados das concepções das participantes quanto a seguinte afirmativa: "Acredito que o trabalho educativo aliado ao uso das tecnologias digitais contribuem para a aprendizagem". Em comparação com a questão anterior, as respostas revelam uma pequena variação: 80,5\% (29) concordam com a afirmativa; 8,3\% (3) concordam parcialmente indicando que há reservas quanto à contribuição das TIC para a aprendizagem do aluno e 11,1\% (4) se opuseram à afirmação. Essa variação é analisada sob a perspectiva de que, quando o uso das TIC refere-se à aprendizagem do aluno, há um aumento de oposição a afirmativa, observado pelas respostas de discordância de $1(2,7 \%)$ para $4(11,1 \%)$.

As questões 4 e 5 apresentam as habilidades tecnológicas pessoais e conhecimento do uso das TIC na prática pedagógica. Pode-se observar, no gráfico 3 que as habilidades tecnológicas influenciam na decisão quanto ao seu uso em situações educativas observando que o número de respostas nessas duas questões é idêntico: $55,5 \%$ (20) concordam que têm facilidade e conhecimento das TIC para uso pedagógico; $38,8 \%$ (14) concordam parcialmente e 5,5\% (2) discordam.

A questão 6, última deste bloco, objetivou diagnosticar se as intenções de uso mais efetivo e regular das TIC seriam modificadas após a frequência na disciplina. A respeito disso, 69,4\% (25) disseram concordar; 19,4\% (7) disseram concordar parcialmente e $11,1 \%$ (4) disseram discordar. Evidencia-se, nestas respostas, que as professoras participantes, que já se manifestaram anteriormente como não habilidosas com as tecnologias e que as usam de forma limitada em seu trabalho pedagógico, afirmavam que continuariam com a mesma concepção de uso, mesmo após a conclusão da disciplina.

Vale ressaltar, que este questionário foi aplicado no início da disciplina. Partimos da coleta de dados que caracterizassem as participantes da pesquisa, sua proficiência digital e as concepções sobre o uso das TIC na educação, pois esses dados serviriam de subsídio para o planejamento das atividades da disciplina. Optamos por elencar atividades que continham algumas estratégias ativas sugeridas por, Bergmann e Sams (2017), Bacich e Moran (2018), Filatro e Cavalcanti (2018) e inserimos outras ações que seriam essenciais ao processo, como a reflexão sobre os papéis assumidos por alunos e professores em sala de aula e a organização do tempo e espaço para uma aula mais ativa. Para isso, foram elaboradas atividades desenvolvidas nas aulas presenciais e on-line, por meio do ambiente Unasp Virtual criado na plataforma Moodlerooms, que contemplaram as seguintes estratégias e recursos: Mapa Mental, Peer Instruction, Infográfico, Brainstorming, Flipped Classroom e as ferramentas digitais Kahoot, Canva, Mind Map.

Ao final da disciplina, foi aplicado o Q2, também criado no aplicativo Google Formulário, visando à recolha de dados sobre a reflexão das participantes quanto ao desempenho na disciplina e os conhecimentos construídos quanto ao uso pedagógico das TIC em processos educacionais, bem como sua concepção sobre esse uso após participação na disciplina.

\section{Discussão e resultados}

Os resultados deste estudo foram construídos a partir da análise e comparação dos 
dados coletados mediante a utilização dos instrumentos de pesquisa. As respostas obtidas em Q1 foram apresentadas e discutidas na sessão anterior e serviram de subsídios para a condução metodológica da disciplina. Os dados oriundos das repostas coletadas em Q2 permitiram a análise comparativa entre as concepções docentes apresentadas no início da disciplina para o uso das TIC e demonstraram uma forte tendência no uso mais efetivo e regular das tecnologias na prática pedagógica, evidenciando uma alteração nas concepções dessas docentes em comparação às respostas do Bloco III, em Q1(Gráfico 3).

O gráfico 4 demonstra essa intencionalidade, por meio das respostas à questão 1 do Q2: "Com base em seu conhecimento sobre tecnologia educativa no início da disciplina e seu conhecimento atual, você considera que irá incorporar as tecnologias em sua prática pedagógica?".

Gráfico 4 - Intencionalidade docente para o uso das TIC, ao término da disciplina.

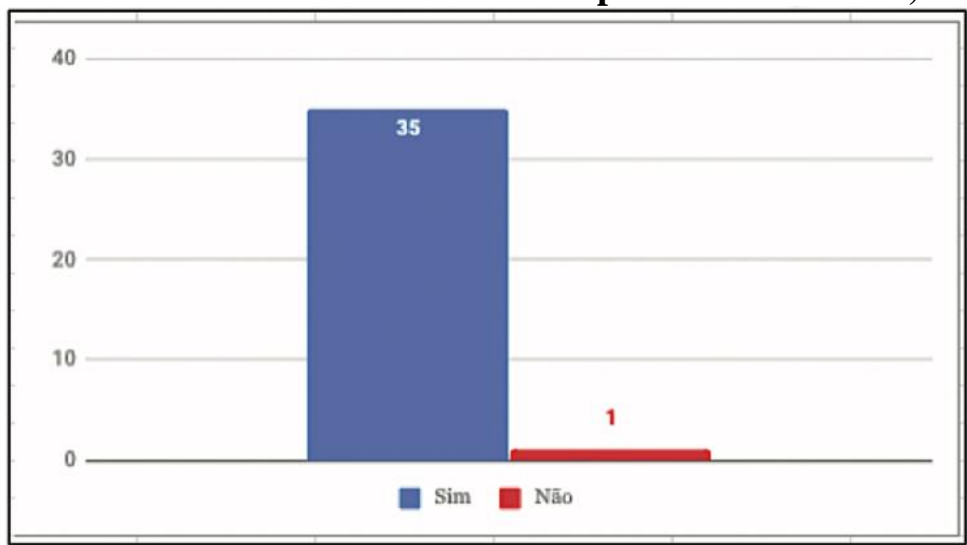

Fonte: Gráfico extraído da questão 1, do Q2, feito no aplicativo Google Formulários.

Comparando com os dados apresentados na questão 6 do Q1 (Gráfico 3), verificamos uma considerável mudança de concepção por parte das participantes, onde havia 4 participantes que afirmavam que não iriam utilizar as TIC em suas aulas contra 1 participante que continua com a mesma concepção, ao final da disciplina. No entanto, ainda que haja toda uma intencionalidade nesse uso, notamos uma latente insegurança de caráter técnico e pedagógico sobre como realizar essa prática. O gráfico 5 traz os dados verificados para essa análise. As respostas são oriundas de questões objetivas de múltipla escolha entre variáveis que iam do nível "fraco" ao "excelente". Este bloco de questões teve o objetivo de verificar e comparar as concepções docentes e habilidades digitais para uso das TIC, após a formação recebida.

\section{Gráfico 5 - Contribuição do curso na formação docente para uso das TIC}




\section{Contribuição da disciplina na formação docente para uso das TIC}

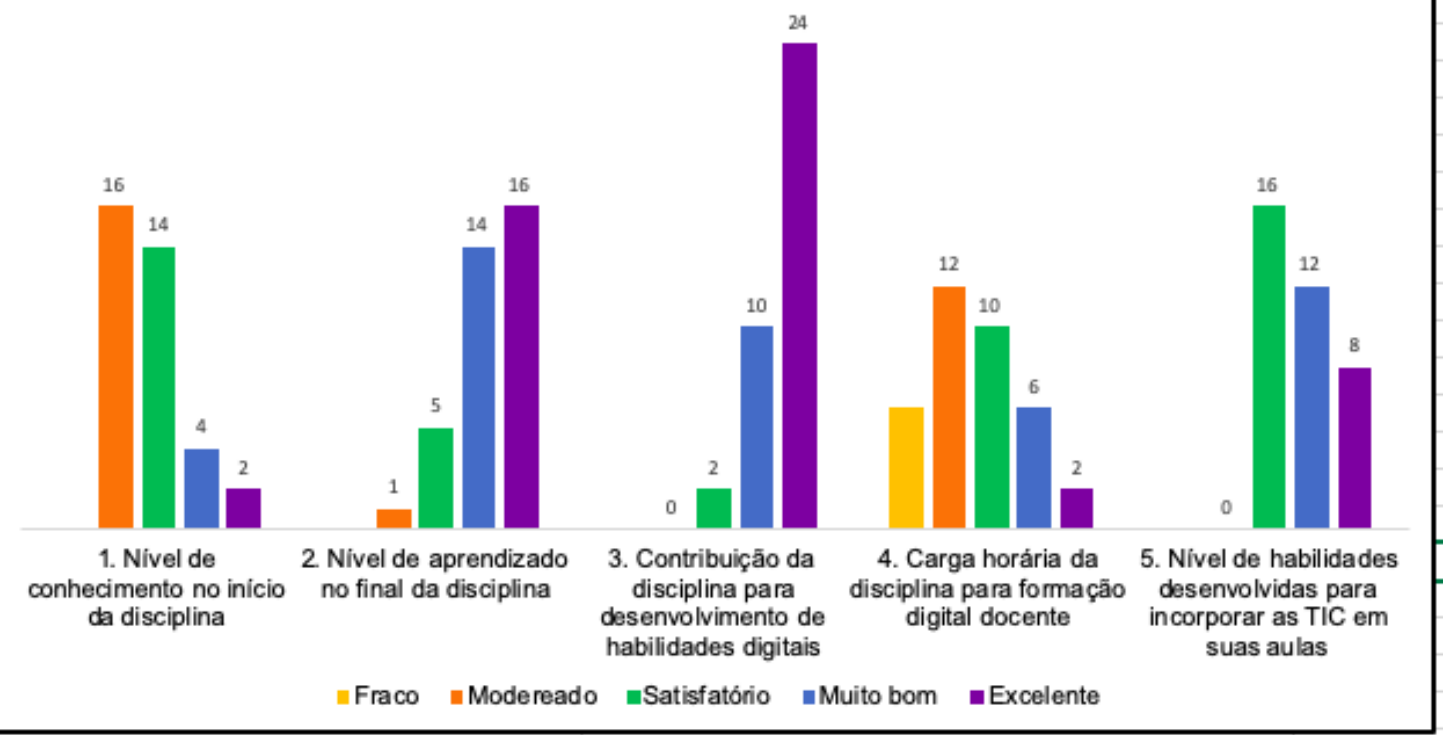

Fonte: Gráfico extraído do Q2, feito na plataforma Google Formulários.

As respostas obtidas a partir desse bloco de questões nos levam a identificar que as professoras partem da concepção sobre a tecnologia como algo a ser aplicado, em vez de integrada as práticas pedagógicas capazes de promover processos inovadores e mais centrados nos alunos (Filatro \& Cavalcanti, 2018). Também foi possível verificar a percepção das professoras quanto ao próprio processo de aprendizagem e a concepção sobre a importância de uma formação continuada. Essa percepção pode ser verificada nas respostas das docentes para a questão 4 deste bloco que evidenciam o dilema sobre a função das TIC na educação, o trabalho pedagógico por meio desses recursos e a necessidade de formação para ampliar os conhecimentos nesta área. É importante reiterar que consideramos a carga horária de $30 \mathrm{~h}$ da disciplina um começo para a formação tecnológica do docente, mas não o suficiente para que todas sintam-se confiantes e confortáveis para incorporar novos modos de ensinar e aprender, por meio de metodologias ativas aliadas às TIC.

Concluímos que os dados coletados nos questionários 1 e 2 revelam que os saberes acionados, aliados à metodologia adotada nas aulas, contribuíram para a reflexão docente sobre as práticas pedagógicas e o uso das TIC em contextos educativos.

\section{Considerações Finais}

Este trabalho teve como objetivo principal conhecer e analisar as concepções do uso das TIC no processo de ensino e aprendizagem de um grupo de 36 professoras da Educação Infantil e do Ensino Fundamental I de seis escolas Adventistas da cidade de São Paulo/SP, Brasil. O estudo dessa temática é relevante pelo impacto das TIC no contexto social e cotidiano das pessoas que, desde o final dos anos 1990, vêm alterando os modos de pensar a educação. Notamos que, atualmente, há uma maior consciência quanto ao uso das TIC para fins educativos, mas ainda há muito o que se fazer para sua integração no processo de ensino e aprendizagem.

Os resultados obtidos demonstraram que a maioria das professoras, participantes desse estudo, adota e percebe a importância das tecnologias em suas atividades 
cotidianas, mas ainda não sabe exatamente integrá-las à sua prática docente. Tais profissionais manifestaram a importância do uso pedagógico das TIC para um aprendizado mais significativo e inovador na sala de aula e expressaram a necessidade de terem uma formação continuada que possa contribuir para o uso de metodologias ativas e das TIC na prática docente.

Compreendemos que a utilização das TIC em situações de ensino e aprendizagem ocorre a partir de mudanças paulatinas, em práticas adotadas em sala de aula, no uso de ambientes on-line, na identificação do uso mais efetivo dos recursos tecnológicos para um aprendizado mais significativo, na avaliação desses recursos, no trabalho em parcerias com outros docentes, permitindo ao profissional professor, aumentar seu repertório de ações pedagógicas e inovar em sua prática docente.

Com base nos resultados obtidos neste estudo, vemo-nos estimuladas a prosseguir em novas investigações. Sabemos que este foi um primeiro passo nessa direção e que ainda há muito o que se fazer. As mudanças de concepção não são determinadas pelo simples uso das tecnologias, discutido em apenas um curso, mas sim, pela apropriação crítica e criativa na integração das TIC na prática pedagógica (Bacich \& Moran, 2018).

\section{REFERÊNCIAS}

ALMEIDA, M. E. B.; MORAN, J. M. (org.) Integração das tecnologias na educação. Salto para o futuro. TV Escola Brasil. Brasília: Secretaria de Educação a Distância - Seed, 2005. Disponível em http://portal.mec.gov.br/seed/arquivos/pdf/iniciaissf.pdf. Acesso em: 20 Mai. 2019.

BACICH, L.; MORAN, J. M. (org.) Metodologias ativas para uma educação inovadora: uma abordagem teórico-prática. Porto Alegre: Penso, 2018.

BATES, T. Educar na era Digital. Artesanato Educacional, São Paulo, 2016.

BEHAR, P. A. (org). Modelos pedagógicos em educação a distância. Porto Alegre: Artmed, 2009.

BEHRENS, M. A. Projetos de aprendizagem colaborativa num paradigma emergente. in: MORAN, J. M. Novas tecnologias e mediação pedagógica. Campinas, SP: Papirus, 2000.

BERGMANN, J. \& SAMS, A. Sala de aula invertida: uma metodologia ativa de aprendizagem. Rio de Janeiro: LTC, 2017.

BRASIL. Ministério da Educação. Proposta de diretrizes para a formação inicial de professores da educação básica em cursos de nível superior. Brasília: SEF/MEC, 2000. Disponível em http://portal.mec.gov.br/cne/arquivos/pdf/basica.pdf

FILATRO, A \& CAVALCANTI, C. C. Metodologias Inov-ativas na educação presencial, a distância e corporativa. Saraiva Uni, São Paulo, 2018.

GAUTHIER, C. et al. Por uma teoria da pedagogia: pesquisas contemporâneas sobre o saber docente.

2. ed. Ijuí: Editora Unijuí, 2006.

GUTIERREZ, F. Linguagem total - uma pedagogia dos meios de comunicação. São Paulo: Summus, 1978.

SCHÖN, D. A. Educando o profissional reflexivo: um novo design para o ensino e a aprendizagem. Porto Alegre: Penso Editora, 2009.

TARDIF, M. Saberes docentes e formação profissional. 4. ed. Rio de Janeiro: Vozes, 2002. 